\title{
Attitude of Working Mothers to Exclusive Breastfeeding in Calabar Municipality, Cross River State, Nigeria
}

\author{
I. A. Ekanem \\ Department of Medical Laboratory Science, University of Calabar, Nigeria \\ A. P. Ekanem \\ Institute of Oceanography, University of Calabar, Nigeria \\ Tel: 234-803-792-8430Ｅ-mail: albertekanem@yahoo.com \\ A. Asuquo \\ Department of Medical Laboratory Science, University of Calabar, Nigeria \\ V. O. Eyo \\ Institute of Oceanography, University of Calabar, Nigeria
}

$\begin{array}{lc}\text { Received: February 27, } 2012 & \text { Accepted: March 14, } 2012 \quad \text { Published: May 1, } 2012 \\ \text { doi:10.5539/jfr.v1n2p71 } & \text { URL: http://dx.doi.org/10.5539/jfr.v1n2p71 }\end{array}$

\begin{abstract}
Attitude of working mothers on breastfeeding was studied between December, 2011 and February, 2012 in Calabar Municipality, Cross River State, Nigeria. One hundred willing mothers were interviewed using self-administered questionnaires, for literate mothers and oral administration of questionnaires to illiterate mothers. Data were analyzed using student's t-test and chi-square statistics. Our results have confirmed that some factors such as age, tribe, religion, occupation, marital status, educational status, health status, socio-economic status, attendance at anti-natal clinics, number of children and diverse opinions have affected the attitudes of working mothers towards EBF. We concluded that attitude of working mothers to EBF is influenced by some demographic and socio-economic factors.
\end{abstract}

Keywords: Exclusive Breastfeeding, Working Mothers

\section{Introduction}

Breastfeeding has been accepted as the most vital intervention for reducing infant mortality and ensuring optimal growth and development of children (Gupta \& Arora, 2007). Breastfeeding is the ideal method suited for the physiological and psychological needs of an infant (Subbiah, 2003). It is estimated that sub-optimal breastfeeding, especially non-exclusive breastfeeding in the first 6 months of life, results in 1.4 million deaths and $10 \%$ of the disease burden in children younger than 5 years of age (WHO, 2009). Exclusive breastfeeding (EBF) for the first 6 months of life improves the growth, health and survival status of newborns (WHO, 2003) and is one of the most natural and best forms of preventive medicine (WHO, 2001). EBF plays a pivotal role in determining the optimal health and development of infants, and is associated with a decreased risk for many early life diseases and conditions, including otitis media, respiratory tract infection, diarrhoea and early childhood obesity (Ip et al., 2007).

It has been estimated that EBF reduces infant mortality rates by up to $13 \%$ in low-income countries (Jones et al., 2003). A large cohort study undertaken in rural Ghana concluded that $22 \%$ of neonatal deaths could be prevented if all infants were put to breast within the first hour of birth (Edmund et al., 2006). Reviews of studies from developing countries show that infants who are not breastfed are 6 to 10 times more likely to die in the first months of life than infants who are breastfed (WHO, 2000; Bahl et al., 2005).

Some researchers have proposed that lack of suitable facilities outside of the home, inconvenience, conflicts at work, family pressure and ignorance adversely affect the willingness of women to practise EBF (Ogbonna et al., 
2000; Forbes et al., 2003). The need to return to work has also been implicated as a factor interfering with EBF (Mahgoub et al., 2002).

The Nigerian government established the Baby-Friendly Hospital Initiative (BFHI) in Benin, Enugu, Maiduguri, Lagos, Jos and Port Harcourt with the aim of providing mothers and their infants a supportive environment for breastfeeding and to promote appropriate breastfeeding practices, thus helping to reduce infant morbidity and mortality rates. Despite these efforts, child and infant mortality continue to be major health issues affecting Nigeria. The infant mortality rate for the most recent five-year period (1999-2003) is about 100 deaths per 1,000 live births. EBF rates in Nigeria continue to fall well below the WHO/UNICEF recommendation of $90 \%$ EBF in children less than 6 months (WHO, 2009).

A more detailed understanding of the attitude of working mothers to exclusive breastfeeding EBF in Nigeria is needed to develop effective interventions to improve the rates of EBF and thus reduce infant mortality. The objective of the present study is to investigate the attitude of working mothers to exclusive breastfeeding (EBF) in Calabar municipality, Cross River State, Nigeria.

\section{Materials and Methods}

The study was carried out from December, 2011 to February 2012 in Calabar municipality, Cross River State. Ethical clearance was obtained from the Ethical committee of the Cross River State Ministry of Health before the study was conducted. Verbal consent was obtained from willing mothers.

A total of 100 mothers were randomly interviewed. A structured questionnaire was self-administered by literate mothers and interviewer-administered for those who are not literate. Information contained in the questionnaire include age, tribe, religion, occupation, marital status, educational status, socio-economic status, attendance of ante-natal clinic, extended family presence, health status, number of children and breastfeeding attitude. Data were analysed using the Statistical Package for Social Sciences (SPSS), version 17.0. Means and proportions were compared using Student's $t$-test and the chi-square test.

\section{Results}

Out of the 100 mothers interviewed, 24 women practised exclusive breastfeeding (EBF), 66 were mixed feeding mothers (MFM) and 10 were non-breastfeeding mothers. Age distribution showed that 10 women were in the age range of 16-26, 65 women were in the age range of 27-37 and 25 women in the range of 38-48 respectively. Exclusive breastfeeding rate was highest in age range of $27-37$ with $66.67 \%$ and lowest in age range of 16-26 with $8.33 \%$.

Exclusive breastfeeding rate evaluated according to tribe was highest amongst the Efiks and Ibibios with 10 (41.66\%) mothers practising EBF followed by Hausa tribe with 7(29.17\%), Igbos with 4(16.67\%) while the Yoruba tribe had the lowest 3(12.5\%). EBF evaluated according to religion was highest amongst the Christians with $18(75 \%)$ mothers practising EBF followed by Muslims with 4(16.67\%), while those who were neither Christians nor Muslims had the lowest EBF of 2(8.33\%). Exclusive breastfeeding rate evaluated according to occupation was highest in self-employed mothers with $16(66.67 \%)$ practising while civil and public servants had the same EBF of $4(16.67 \%)$ each. EBF evaluated according to marital status was highest in married mothers 19 (79.17\%), followed by divorced mothers with 3(12.5\%), while single mothers had the lowest EBF of $2(8.33 \%)$.

EBF evaluated according to educational status was highest in tertiary institutions with $10(41.66 \%)$ mothers followed by primary and secondary institutions with $6(25 \%)$ each while illiterate mothers had the lowest EBF of 2(8.33\%). For socio-economic status, lower class mothers had the highest EBF of 14 (58.33\%) followed by middle class mothers with 6(25\%), while upper class mothers had the lowest EBF of 4(16.67\%). EBF was higher in mothers who attended ante-natal clinics with $20(83.33 \%)$ than mothers who did not attend ante-natal clinics with EBF of 4(16.67\%). EBF was higher in mothers who enjoyed the presence of extended family members with $18(75 \%)$ than mothers without the presence of extended family members with EBF of 6(25\%). EBF was only found in healthy mothers with $24(100 \%)$ while HIV positive mothers, mothers on certain medication and mothers with active and untreated ailment did not practise EBF $0(0 \%)$. Finally, mothers with 1-2 children had the highest EBF of 18(75\%), followed by mothers with 3-4 children with EBF of 4(16.67\%) while mothers with 5 children and above had the lowest EBF of 2(8.33\%). Table 1 shows Frequency and percentage of mothers practising EBF by some selected Socioeconomic and Demographic Characteristics in Calabar municipality.

(Table 1) 


\section{Discussion}

The EBF of $24 \%$ in this study was low but agrees with reports by other workers in Nigeria (Otaigbe et al., 2005); this is in spite of the high level of knowledge about EBF, indicating that some detracting factors may be at play. Mothers between the ages of 27-37 years showed the highest EBF in this study which was significantly $(\mathrm{P}<0.05)$ different from mothers in 16-26 and 38-48years. This may be attributed to inexperience on the part of the younger women, who are also more easily influenced by family pressure. Although mothers from the Efik and Ibibio tribes had the highest EBF in this study, there was no significant difference $(\mathrm{P}>0.05)$ from mothers in other tribes. Smaller family size (1-2 children) had a positive influence on EBF among women than large families (3-5 children). However, this is an indication that mothers can cope better with the demands of EBF when they have fewer babies who are well spaced out; this reduces the likelihood of 'burnout' and maternal exhaustion.

A higher maternal educational level was observed to favour EBF significantly $(\mathrm{P}<0.05)$ as compared to illiterate mothers. This may be informed by their understanding of the health implications of EBF on child's health. This is in support of the findings of Ogbonna et al, 2000.

Attendance of ante-natal clinic enhances mothers' understanding and appreciation of the demands and benefits of EBF, and empowers them to resist external interferences and pressures.

Although extended family members had a higher value of EBF in the study, there was no significant difference $(\mathrm{P}>0.05)$ with mothers without extended family members. Women who were self employed showed the highest EBF as compared to women who were public and civil servants. This shows that the nature of occupation can interfere with EBF since women who were public and civil servants were distracted by their occupation than self employed mothers. This is also in support of Ogbonna et al., 2000.

In our study, $10 \%$ of the women never practised EBF believing that their breast milk was insufficient for babies need. They misinterpreted excessive crying by babies to be an indication of hunger. However, $66 \%$ of mothers who practised mixed feeding believed that their breast milk needs to be supplemented with artificial formulae for fast growth and health of their babies.

Married women were observed to have the highest EBF than singles and divorced mothers. This is an indication that the presence of a husband can have positive influence on EBF. The restraint of few unhealthy mothers from EBF as observed in this study is a reflection of counselling by health workers to safeguard their babies from cross-infections.

The few non-breastfeeding mothers and mixed feeding mothers encountered in this study were having negative opinions towards breastfeeding, seeing it as embarrassing in the public while a few are not willing to carry fallen breast which are likely to come after exclusive breastfeeding and a few are afraid of pains associated with breastfeeding. For these last categories, there are needs for encouragements and support from friends, family members and proper counselling towards attitudinal change in favour of EBF (Kloeblen et al., 2002; Persad \& Mensinger, 2008; Hurley et al., 2008).

The opinions of mothers who are not willing to embark on EBF and those who are partially supporting it should be respected by subtle intervention through proper counselling by health workers. Moreover, government and non governmental agencies should establish crèche close to offices where nursing mothers could have access to breastfeed their babies during official hours.

Government policies towards maternity leave should reflect the need to provide reasonable time for nursing mothers to breastfeed their babies before returning to work.

\section{Referenes}

Bahl, R., Frost, C., Kirkwood, B. R., Karen, E., Martines, J., \& Bhandari N. (2005). Infant feeding patterns and risks of death and hospitalization in the first half of infancy: multicentre cohort study. World Health Organization, 83, 418-426.

Edmond, K. M., Zandoh, C., Quigley, M. A., Amenga-Etego, S., Owusu-Agyei, S., \& Kirkwood, B. R. (2006). Delayed Breastfeeding Initiation Increases Risk of Neonatal Mortality. Pediatrics, 117, e380-e386. http://dx.doi.org/10.1542/peds.2005-1496

Forbes, G. B, Adams-Curtis, L. E., Hamm, N. R., \& White, K. B (2003). Perceptions of the woman who breastfeeds: the role of erotophobia, sexism, and attitudinal variables. Sex Roles: A Journal of Research, 49, 379-388. 
Gupta, A., \& Arora, V. (2007). The State of World's Breastfeeding -Tracking Implementation of the Global Strategy for Infant and Young Child Feeding. International Baby Food Action Network (IBFAN), Asia Pacific. South Asia report.

Hurley, K. M., Black, M. M., \& Papas, M. A. (2008). Variation in breastfeeding behaviours, perceptions, and experiences by race/ethnicity among a low-income statewide sample of Special Supplemental Nutrition Program for Women, Infants and Children (WIC) participants in the United States. Maternal Child Nutrition 4, 95-105. http://dx.doi.org/10.1111/j.1740-8709.2007.00105.x

Ip, S., Chung, M., Raman, G., Chew, P., Magula, N., DeVine, D., Trikalinos, T., \& Lau, J. (2007). Breastfeeding and maternal and infant health outcomes in developed countries. Rockville, MD; US Department of Health and Human Services.

Jones, G., Steketee, R., Black, R., Bhutta, Z., \& Morris, S. (2003). The Bellagio Child Survival Study Group: How many child deaths can we prevent this year? Lancet, 362(19), 65-71. http://dx.doi.org/10.1016/S0140-6736(03)13811-1

Kloeblen-Tarver, A. S., Thompson, N. J., \& Miner, K. R. (2002). Intent to breast-feed: The impact of attitudes, norms, parity and experience. American Journal of Health and Behaviour, 26, 182-187. http://dx.doi.org/10.5993/AJHB.26.3.3

Mahgoub, S. E. O., Bandeke, T., \& Nneypi, M. (2002). Breastfeeding in Botswana: Practices, attitudes, patterns, and the socio-cultural factors affecting them. Journal of Tropical Paediatric, 48, 195-199. http://dx.doi.org/10.1093/tropej/48.4.195

Ogbonna, C., Okolo, A. A., \& Ezeogu, A. (2000). Factors influencing exclusive breastfeeding in Jos, Plateau State, Nigeria. West African Journal of Medicine, 19, 107-110.

Otaigbe, B. E., Alikor, E. A. D., \& Nkanginieme, K. E. O. (2005). Growth pattern of exclusively breastfed infants. Nigerian Journal of Medicine, 14, 137-145.

Persad, M. D., \& Mensinger, J. L. (2008). Maternal breastfeeding attitudes: Association with breastfeeding intent and socio-demographics among urban primiparas. Journal of Community Health, 33, 53-60. http://dx.doi.org/10.1007/s10900-007-9068-2

Subbiah, N. (2003). A Study to assess the Knowledge, Attitude, Practice and Problems of Postnatal Mothers regarding Breastfeeding. Nursing Journal of India, 94(8), 177-179.

World Health Organization (2000). WHO Collaborative Study Team on the Role of Breast-feeding on the Prevention of Infant Mortality. Effect of breastfeeding on infant and childhood mortality due to infectious diseases in less developed countries: a pooled analysis. Lancet, 355, 451-455. http://dx.doi.org/10.1016/S0140-6736(99)06260-1

World Health Organisation (2003). The Global Strategy for Infant and Young Child Feeding. Geneva.

World Health Organization (2009). Infant and young child feeding Model Chapter for textbooks for medical stu-dents and allied health professionals. 
Table 1. Frequency and percentage of mothers practising EBF by Some Selected Socioeconomic and Demographic Characteristics in Calabar municipality

\begin{tabular}{|c|c|c|c|c|}
\hline FACTOR & FREQUENCY & EBF(\%) & Chi -square & P-Value \\
\hline \multicolumn{5}{|l|}{ AGE } \\
\hline $16-26$ & 10 & $2(8.33)$ & & \\
\hline $27-37$ & 65 & $16(66.67)$ & 13.00 & 0.002 \\
\hline \multirow[t]{2}{*}{$38-48$} & 25 & $6(25)$ & & \\
\hline & 100 & 24 & & \\
\hline \multicolumn{5}{|l|}{ TRIBE } \\
\hline Igbo & 30 & $4(16.67)$ & & \\
\hline Efik/Ibibio & 50 & $10(41.66)$ & 5.00 & 0.172 \\
\hline Yoruba & 15 & $3(12.5)$ & & \\
\hline \multirow[t]{2}{*}{ Hausa } & 5 & $7(29.17)$ & & \\
\hline & 100 & 24 & & \\
\hline \multicolumn{5}{|l|}{ RELIGION } \\
\hline Christian & 90 & $18(75)$ & & \\
\hline Muslim & 5 & $4(16.67)$ & 19.00 & 0.000 \\
\hline None of the above & $\begin{array}{r}5 \\
100\end{array}$ & $2(8.33)$ & & \\
\hline \multicolumn{5}{|l|}{ OCCUPATION } \\
\hline Civil servant & 53 & $4(16.67)$ & & \\
\hline Public servant & 30 & $4(16.67)$ & 2.667 & 0.102 \\
\hline \multirow{2}{*}{ Self employed } & 17 & $16(66.67)$ & & \\
\hline & 100 & 24 & & \\
\hline \multicolumn{5}{|l|}{ MARITAL SERVICE } \\
\hline single & 15 & $2(8.33)$ & & \\
\hline married & 6 & 19(79.17) & 22.75 & 0.000 \\
\hline \multirow[t]{2}{*}{ divorced } & 9 & $3(12.5)$ & & \\
\hline & 100 & 24 & & \\
\hline \multicolumn{5}{|l|}{ EDUCATIONAL STATUS } \\
\hline Illiterate & 20 & $2(8.33)$ & & \\
\hline Primary & 5 & $6(25)$ & & \\
\hline Secondary & 35 & $6(25)$ & 7.0 & 0.300 \\
\hline \multirow{2}{*}{ Tertiary } & 40 & $10(41.66)$ & & \\
\hline & 100 & 24 & & \\
\hline \multicolumn{5}{|l|}{ SOCIO-ECONOMIC STATUS } \\
\hline Lower class & 28 & $14(58.33)$ & & \\
\hline Middle class & 52 & $6(25)$ & 7.0 & 0.300 \\
\hline \multirow{2}{*}{ Upper class } & 20 & $4(16.67)$ & & \\
\hline & 100 & 24 & & \\
\hline \multicolumn{5}{|c|}{ ATTENDANCE OF ANTE-NATAL CLINIC } \\
\hline Yes & 86 & $20(83.33)$ & & \\
\hline \multirow{2}{*}{ No } & 14 & $4(16.67)$ & 10.67 & 0.001 \\
\hline & 100 & 24 & & \\
\hline EXTENDED FAMILY PRESENCE & & & & \\
\hline Yes & 77 & $18(75)$ & & \\
\hline No & 23 & $6(25)$ & 6.0 & 0.014 \\
\hline & 100 & 24 & & \\
\hline HEALTH STATUS & & & & \\
\hline Healthy mothers & 70 & $24(100)$ & & \\
\hline HIV positive mothers & 15 & $0(0)$ & - & - \\
\hline Mothers on certain medication & 5 & $0(0)$ & & \\
\hline Others with active, untreated ailment & 10 & $0(0)$ & & \\
\hline & 100 & 24 & & \\
\hline NO. OF CHILDREN & & & & \\
\hline $1-2$ & 60 & $18(75)$ & & \\
\hline $3-4$ & 32 & $4(16.67)$ & 19.00 & 0.000 \\
\hline$>5$ & 8 & $2(8.33)$ & & \\
\hline & 100 & 24 & & \\
\hline BREASTFEEDING ATTITUDE & & & & \\
\hline EBF from $0-6$ months & 24 & & & 0.000 \\
\hline MFM from 0 -6months & 66 & & 50.94 & \\
\hline Non- breastfeeding mothers & 10 & & & \\
\hline & 100 & & & \\
\hline
\end{tabular}

EBF=Exclusive Breast Feeding; MFM=Mixed Breast Feeding. 